
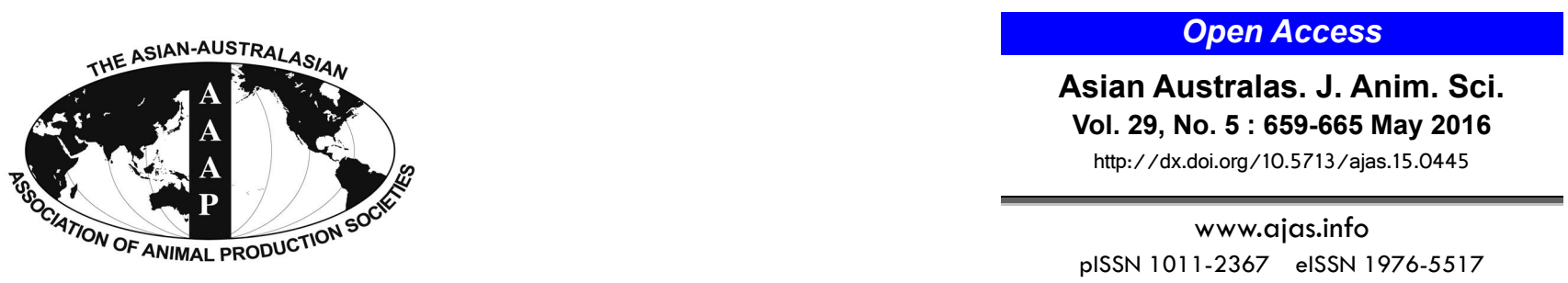

\title{
Effects of Three Feeding Systems on Production Performance, Rumen Fermentation and Rumen Digesta Particle Structure of Beef Cattle
}

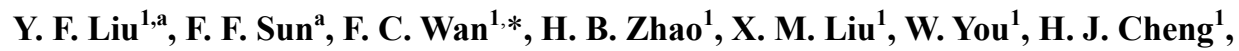 \\ G. F. Liu ${ }^{1}$, X. W. Tan ${ }^{1}$, and E. L. Song ${ }^{1}$ \\ Institute of Animal Science and Veterinary Medicine, Shandong Academy of Agricultural Sciences, \\ Ji'nan, Shandong 250100, China
}

\begin{abstract}
The effects of three different feeding systems on beef cattle production performance, rumen fermentation, and rumen digesta particle structure were investigated by using 18 Limousin (steers) with a similar body weight $(575 \pm 10 \mathrm{~kg})$ in a 80 -d experiment. The animals were equally and randomly divided into three treatment groups, namely, total mixed ration group (cattle fed TMR), SI1 group (cattle fed concentrate firstly then roughage), and SI2 group (cattle fed roughage firstly then concentrate). The results showed that the average daily gain was significantly higher in cattle receiving TMR than in those receiving SI1 and SI2 ( $<0.05)$. Consumption per $\mathrm{kg}$ weight gain of concentrate, silage, and combined net energy (NEmf) were significantly decreased when cattle received TMR, unlike when they received SI1 and SI2 $(p<0.05)$, indicating that the feed efficiency of TMR was the highest. Blood urea nitrogen (BUN) was significantly decreased when cattle received TMR compared with that in cattle receiving SI1 $(\mathrm{p}<0.05)$, whereas there was no difference compared with that in cattle receiving SI2. Ammonia nitrogen concentration was significantly lower in cattle receiving TMR than in those receiving SI1 and SI2 $(\mathrm{p}<0.05)$. The rumen area of cattle that received TMR was significantly larger than that of cattle receiving SI1 ( $<0.05)$, but there was no difference compared with that of cattle receiving SI2. Although there was no significant difference among the three feeding systems in rumen digesta particle distribution, the TMR group trended to have fewer large- and medium-sized particles and more small-sized particles than those in the SI1 and SI2 groups. In conclusion, cattle with dietary TMR showed increased weight gain and ruminal development and decreased BUN. This indicated that TMR feeding was more conducive toward improving the production performance and rumen fermentation of beef cattle. (Key Words: Beef Cattle, Feeding Systems, Production Performance, Rumen Fermentation, Rumen Digesta Particle)
\end{abstract}

\section{INTRODUCTION}

The traditional way of feeding cattle is to separately provide concentrate and roughage; however, controlling the proportion of concentrate and roughage is difficult. Total mixed ration (TMR) has been reported to increase the body weight (BW) gain in growing and mature beef cattle; TMR feeding is known to increase feed intake and improve $\mathrm{N}$ use (Moya et al., 2011). Cows on TMR treatment gained more

\footnotetext{
* Corresponding Author: F. C. Wan. Tel: +86-13869191170, Fax:+86-53188967665, E-mail: wanfc@sina.com

${ }^{1}$ Shandong Key Lab of Animal Disease Control and Breeding, Ji'nan, Shandong 250100, China.

${ }^{\text {a }}$ These authors contributed equally to this work.

Submitted May 21, 2015; Revised Jul. 25, 2015; Accepted Aug. 24, 2015
}

BW and had higher body condition compared with cows fed pasture plus concentrate (PC); further, plasma and milk urea nitrogen were lower in cows fed TMR than in those fed PC (Bargo et al., 2002a, b). Feedlot cattle were fed TMR containing a high proportion of grains to maximize their growth performance and profitability (Charlton et al., 2011).

TMR diets also usually contain a base level of physically effective fiber to reduce the risk of subclinical ruminal acidosis and enhance rumen function (Boguhn and Rodehutscord, 2006); this is attributed to the rapid production of volatile fatty acids (VFA) as a result of microbial fermentation of feed. Previous studies have reported that ruminal $\mathrm{NH}_{3}-\mathrm{N}$ concentration was lower in cows fed TMR than in those fed PC (Bargo et al., 2002a, b). Ruminal $\mathrm{NH}_{3}-\mathrm{N}$ losses were reduced when pasture and 
TMR were combined; however, this combination decreased the ruminal digestion of pasture, indicating the presence of associative effects in the rumen (Moya et al., 2011).

TMR has been widely used to feed cattle in Israel, the United States, Italy, Canada, and other countries. In China, some large-scale beef cattle farms have gradually initiated the use of TMR. However, the adverse effects of TMR feeding remain unclear. Further, there is limited information on the effects of TMR on the critical size of particles that can escape from the rumen in cattle.

Therefore, this study aimed to determine the effects of TMR on the growth performance, rumen fermentation parameters, and rumen digesta particle structure of beef cattle to compare the effects of different systems used to feed cattle and improve beef production.

\section{MATERIALS AND METHODS}

\section{Animals, experimental design and diets}

Eighteen Limousin (steers) beef cattle, with an initial BW of $575 \pm 10 \mathrm{~kg}$, were used in a 80 -d experiment. The trial included 15 days of adaptation period to diet followed by feeding the experimental treatments. The experiment was conducted in a complete randomized design with 3 dietary treatments and 6 replications. Treatments included i) TMR group, ii) SI1 group (cattle fed concentrate firstly then roughage), and iii) SI2 group (cattle fed roughage firstly then concentrate). Cattle used in the experiments were cared for in accordance with the guidelines for the care and use of laboratory animals described by the Animal Nutrition Research Institute of Shandong Agricultural University and the Ministry of Agriculture of China. All cattle were feed twice daily at 05:00 $\mathrm{h}$ and 15:00 $\mathrm{h}$, in equal portions. Clean drinking water was available at all times and changed twice daily. Ingredient and chemical composition (mean \pm standard deviation) of the concentrate used to supplement the cattle are shown in Table 1. Chemical composition of TMR used to supplement the cattle is shown in Table 2.

\section{Growth and slaughter performance}

Cattle were weighed $2 \mathrm{~h}$ before feed delivery at the beginning and the end of the study. The average daily gain (ADG) of each cattle was determined by dividing BW gain by the number of days on feed. Total dry matter intake (DMI) was also estimated during the three treatments. Feed efficiency was calculated individually as G:F ( $\mathrm{kg}$ of BW gain divided by $\mathrm{kg}$ of DMI over the experiment). Cattle were slaughtered for body composition analysis at the slaughterhouse. Cattle were weighed before slaughter, which was 14 to $16 \mathrm{~h}$ after the previous afternoon feeding; cattle were not fed on the morning of slaughter. This weight was assumed to represent shrunk weight. The heart, kidneys, liver, and the empty digestive tract were weighed
Table 1. Ingredient composition (mean $\pm \mathrm{SD}$ ) of the concentrate used to supplement the cattle

\begin{tabular}{lc}
\hline Items & Concentrate \\
\hline Ingredients composition (\%) & 66.0 \\
Corn & 15.0 \\
Cottonseed cake & 12.0 \\
Wheat bran & 1.0 \\
Sodium bicarbonate & 4.0 \\
Premix & 2.0 \\
DDGS & \\
Chemical composition & $88.53 \pm 4.4$ \\
DM (\%) & $11.75 \pm 0.4$ \\
CP $(\%$ of DM) & $2.04 \pm 0.5$ \\
EE $(\%$ of DM) & $5.99 \pm 0.2$ \\
Ash $(\%$ of DM) & 15.78 \\
NEmf $(\mathrm{MJ} / \mathrm{kg})$ &
\end{tabular}

SD, standard deviation; DDGS, dry distillers grains with solubles; DM, dry matter; $\mathrm{CP}$, crude protein; EE, ether extract; NEmf, combined net energy.

${ }^{1}$ The premix provided the following per $\mathrm{kg}$ of concentrate: Vit. A, 700 KIU; Vit. D, $370 \mathrm{KIU}$; Vit. E, 1,750 IU; Mn, 6,000 mg; Zn, 6,000 mg; $\mathrm{Fe}, 8,750 \mathrm{mg}$; $\mathrm{Cu}, 875 \mathrm{mg}$; Se, $87.5 \mathrm{mg}$; I, $87.5 \mathrm{mg}$; Co, $25 \mathrm{mg}$; urease inhibitors, $3,750 \mathrm{mg}$.

individually, and then were composited and ground as the visceral fraction. The entire viscera-free carcass, including head, hide, hooves, and tail, was ground and is referred to as the viscera-free carcass fraction. The main indexes were calculated according to the following formula:

Dressing percentage $(\%)$

$=$ Carcass weight $/$ live weight before slaughtering $\times 100 \%$

Net meat percentage $(\%)$

$=$ Net meat weight $/$ live weight before slaughtering $\times 100 \%$

Meat:Bone (\%)

$=$ Net meat weight $/$ net bone weight $\times 100 \%$

Table 2. Chemical composition of basal diet used to supplement the cattle

\begin{tabular}{|c|c|}
\hline & Concentrate \\
\hline Mixed concentrate (\% of DM) & 30.95 \\
\hline Whole corn silage $^{1}(\%$ of DM) & 69.05 \\
\hline \multicolumn{2}{|l|}{ Chemical composition } \\
\hline $\mathrm{DM}(\%)$ & 44.66 \\
\hline $\mathrm{CP}(\%$ of $\mathrm{DM})$ & 10.30 \\
\hline $\mathrm{EE}(\%$ of $\mathrm{DM})$ & 1.88 \\
\hline Ash $(\%$ of DM) & 7.80 \\
\hline $\operatorname{NEmf}(\mathrm{MJ} / \mathrm{kg})$ & 5.16 \\
\hline $\mathrm{Ca}(\%$ of $\mathrm{DM})$ & 0.48 \\
\hline $\mathrm{P}(\%$ of $\mathrm{DM})$ & 0.59 \\
\hline
\end{tabular}

DM, dry matter; CP, crude protein; EE, ether extract; NEmf, combined net energy .

${ }^{1}$ Composition was $30.84 \%$ DM, $7.11 \%$ CP, $1.30 \%$ EE, $5.39 \%$ Ash, 3.56 $\mathrm{MJ} / \mathrm{kg}$ MEmf, $0.33 \% \mathrm{Ca}$, and $0.41 \% \mathrm{P}$ based on DM basis. 


\section{Blood variables}

Blood samples were obtained via jugular venipuncture immediately before feed delivery at 0500 on $\mathrm{d} 0$ and at the end of the study. The blood was transferred to a microhematocrit capillary tube, and the tube was centrifuged at room temperature for $5 \mathrm{~min}$ at $1,500 \times \mathrm{g}$ to separate serum and stored at $-20^{\circ} \mathrm{C}$. Glucose (Glu), triglycerides (TG), blood urea nitrogen (BUN), total cholesterol (TC), and nonesterified fatty acids (NEFA) were determined using Automatic Biochemical Analyzer (7170S; HITACHI, Tokyo, Japan). Insulin (INS) was determined using competitive radioimmunoassay with Automatic Biochemical Analyzer (Elecsys 2010; HITACHI, Japan). The kits were purchased from Nanjing Jiancheng bio Limited.

\section{Ruminal pH and volatile fatty acids measurements}

One hundred $\mathrm{ml}$ rumen fluid samples were obtained when cattle slaughtered $2 \mathrm{~h}$ after feeding at the end of the trial. The $\mathrm{pH}$ of the ruminal fluid was determined immediately after collection using a pH meter (PHB-10, Shanghai Shuangxu Electronic Co., Shanghai, China). Part of the filtered samples was stored at $-20^{\circ} \mathrm{C}$ to prepare for measuring ammonia nitrogen $\left(\mathrm{NH}_{3}-\mathrm{N}\right)$ concentration. Another part of the filtered samples were centrifuged at room temperature for $10 \mathrm{~min}$ at $10,000 \times g$ to obtain supernatant, which was added $25 \%$ phosphoric acid by $4: 1$ (supernatant:acid). The supernatant was prepared after standing for $30 \mathrm{~min}$, and then centrifuged for $10 \mathrm{~min}$ at $20,000 \times$ g. Ruminal VFA were quantified using gas chromatography (Agilent Technologies 7890A; Santa Clara, CA, USA) with crotonic acid as an internal standard and a capillary column $(30 \mathrm{~m} \times 0.32 \mathrm{~mm} \times 0.5 \mathrm{~m}$; Phenomenex Inc., Torrance, CA, USA) by using flame ionization detection.

\section{Rumen tissue sampling}

Eighteen Limousin (steers) beef cattle (6/treatment) were euthanized at the end of the experiment by using captive bolt stunning and exsanguinations. Digestive tracts were harvested, emptied, and rinsed with cold water. Rumen tissue samples were collected for analysis of papillae length, papillae width, and rumen wall thickness according to Lesmeister et al. (2004).

\section{Measurement of particle size distribution and calculation of mean particle size}

The rumen was removed rapidly after the cattle were slaughtered and then quick-frozen without changing its internal structure and external shape. Eight samples of each cattle were evenly divided according to the length (horizontal) and width (vertical) of the cattle body and stored at $-20^{\circ} \mathrm{C}$. The screens used for wet sieving (Sieving
Machine, DZYS600-2600, Xinxiang Dongzhen Machinery Co., Ltd., Henan, China) were 4, 2, 1, 0.5, and $0.25 \mathrm{~mm}$ apertures $(20 \mathrm{~cm}$ diameter, $8 \mathrm{~cm}$ depth) to analyze rumen digesta particle size according to Waghorn et al. (1989). Aggregation of the particles was reduced by immersing the sample in water for $30 \mathrm{~min}$ to dissolve. The five sieve and chassis were arranged from top to bottom according to pore size. Each fresh sample was first placed on the top sieve (aperture, $4.0 \mathrm{~mm}$ ), following which the samples were left on every sieve with horizontal vibration for drying at $65^{\circ} \mathrm{C}$ overnight. Subsequently, the rumen digesta particles remaining on each layer of the sieves after drying were weighed and crushed. The dry matter (DM) percentage was calculated according to the following formula:

DM percentage (\%) of digesta particles remaining on a sieve layer $=\mathrm{DM}$ of particles stranded in each sieve/total $\mathrm{DM} \times 100 \%$

\section{Statistical analyses}

Data for intake, growth, and blood parameters were analyzed in a randomized complete block design, and the rumen development data were analyzed as a completely randomized design. A repeated measures analysis was conducted using the MIXED procedure of SPSS 17.0, with block and calf used as the random effect for the growth and rumen development analyses, respectively.

\section{RESULTS}

\section{Growth and slaughter performance}

Table 3 shows that the average daily feed intake and ADG were significantly higher in cattle receiving TMR $(22.81 \pm 0.22 \mathrm{~kg}$ and $0.98 \pm 0.09 \mathrm{~kg}$, respectively) than in those receiving SI1 $(20.01 \pm 0.16 \mathrm{~kg}$ and $0.81 \pm 0.07 \mathrm{~kg})$ and SI2 $(21.17 \pm 0.15 \mathrm{~kg}$ and $0.90 \pm 0.06 \mathrm{~kg} ; \mathrm{p}<0.05)$. Cattle receiving TMR consumed $13.42 \%$ and $6.59 \%$ less total DMI than those receiving SI1 and SI2 treatment, respectively $(p<0.05)$. Further, cattle on TMR treatment consumed less concentrate and silage than cattle on SI1 and SI 2 treatments $(p<0.05)$. Table 4 shows that the dressing percentage was higher in cattle receiving TMR than in those receiving SI1 and SI2 $(\mathrm{p}<0.05)$.

\section{Blood biochemical indices}

The cattle on TMR treatment had lower BUN concentration $(2.33 \pm 0.11 \mathrm{mmol} / \mathrm{L})$ than those on $\mathrm{SI}$ $(2.77 \pm 0.31 \mathrm{mmol} / \mathrm{L} ; \mathrm{p}<0.05)$ and SI $(2.46 \pm 0.27 \mathrm{mmol} / \mathrm{L}$; $\mathrm{p}>0.05$ ) treatments (Table 5). However, there was no significant difference in TG, TC, NEFA, INS, and Glu. concentrations among the three treatments. 
Table 3. Effects of feeding methods on the production performance of steers

\begin{tabular}{|c|c|c|c|c|}
\hline Groups & TMR & $\mathrm{SI}^{1}{ }^{1}$ & $\mathrm{SI} 2^{2}$ & p-value ${ }^{3}$ \\
\hline ADG (kg) & $0.98 \pm 0.09^{\mathrm{a}}$ & $0.81 \pm 0.07^{\mathrm{c}}$ & $0.90 \pm 0.06^{\mathrm{b}}$ & 0.034 \\
\hline ADFI (kg) & $22.81 \pm 0.22^{\mathrm{a}}$ & $20.01 \pm 0.16^{\mathrm{b}}$ & $21.17 \pm 0.15^{\mathrm{b}}$ & 0.045 \\
\hline \multicolumn{5}{|c|}{ Consumption per kg weight gain } \\
\hline Concentrate (kg) & $7.10 \pm 0.43^{\mathrm{c}}$ & $8.47 \pm 0.12^{\mathrm{a}}$ & $7.63 \pm 0.12^{\mathrm{b}}$ & 0.028 \\
\hline Silage $(\mathrm{kg})$ & $18.24 \pm 0.01^{\mathrm{c}}$ & $19.80 \pm 0.03^{\mathrm{a}}$ & $19.09 \pm 0.01^{\mathrm{b}}$ & 0.026 \\
\hline $\mathrm{DM}(\mathrm{kg})$ & $10.77 \pm 0.02^{\mathrm{b}}$ & $12.44 \pm 0.17^{\mathrm{a}}$ & $11.53 \pm 0.11^{\mathrm{ab}}$ & 0.048 \\
\hline $\mathrm{CP}(\mathrm{kg})$ & $1.09 \pm 0.02$ & $1.27 \pm 0.07$ & $1.16 \pm 0.17$ & 0.078 \\
\hline NEmf (MJ) & $63.68 \pm 0.02^{\mathrm{c}}$ & $74.74 \pm 0.13^{\mathrm{a}}$ & $68.12 \pm 0.14^{\mathrm{b}}$ & 0.045 \\
\hline
\end{tabular}

TMR, total mixed ration; ADG, average daily gain; ADFI, average daily feed intake; DM, dry matter; CP, crude protein; NEmf, combined net energy.

${ }^{1}$ SI1, cattle fed concentrate firstly then roughage. ${ }^{2}$ SI2, cattle fed roughage firstly then concentrate. ${ }^{3}$ Linear effects of three feeding systems.

${ }^{a, b, c}$ Means with different superscripts in the same row are significantly different $(\mathrm{p}<0.05)$.

\section{Rumen fermentation profile}

Ruminal fermentation measures are shown in Table 6 . Rumen $\mathrm{pH}$ did not differ among treatments and averaged $6.06(\mathrm{p}>0.05)$. Similar rumen $\mathrm{pH}$ for the three treatments could be related to the lower forage-to-concentrate ratio in the TMR treatment and the limited intake of fiber and high rumen digestibility in both SI1 and SI2 treatments, even though they had a higher forage-to-concentrate ratio. Total VFA concentration did not differ among treatments and averaged $108.10 \mathrm{mmol} / \mathrm{L}(\mathrm{p}>0.05)$. Individual VFA molar proportions did not differ among treatments. The three principal individual VFA proportions averaged 67.43, 24.51, and $16.13 \mathrm{mmol} / \mathrm{L}$ for acetate, propionate, and butyrate, respectively. The acetate/propionate ratio did not differ among treatments. Rumen $\mathrm{NH}_{3}-\mathrm{N}$ concentration was significantly lower in the cattle on TMR $(8.83 \pm 3.10 \mathrm{mg} / 100$ $\mathrm{mL})$ treatment than in those on SI1 $(24.00 \pm 3.89 \mathrm{mg} / 100$ $\mathrm{mL})$ and SI2 $(21.89 \pm 4.53 \mathrm{mg} / 100 \mathrm{~mL})$ treatments $(\mathrm{p}<0.05)$.

\section{Rumen organization development}

The rumen area of cattle who received TMR was significantly larger than that of cattle receiving SI1 $(\mathrm{p}<$ $0.05)$, but there was no difference with those receiving SI2 (Table 7). There was no significant difference in other index among the three treatments.

\section{Rumen digesta particle distribution}

Table 8 shows that, at the horizontal level, rumen particles with large and medium DM percentage ( $\geq 4 \mathrm{~mm}$ and $<4 \mathrm{~mm}, \geq 2 \mathrm{~mm}$, respectively) in the TMR group

Table 4. Effect of feeding methods on carcass performance of steers

\begin{tabular}{|c|c|c|c|c|}
\hline$\overline{\text { Groups }}$ & TMR & $\mathrm{SI}^{1}$ & $\mathrm{SI} 2^{2}$ & p-value ${ }^{3}$ \\
\hline Live weight before slaughtering $(\mathrm{kg})$ & $657.67 \pm 18.33$ & $638.33 \pm 6.13$ & $645.67 \pm 21.38$ & 0.673 \\
\hline Carcass weight $(\mathrm{kg})$ & $355.48 \pm 12.23$ & $338.76 \pm 2.73$ & $348.52 \pm 14.17$ & 0.514 \\
\hline Dressing percentage $(\%)$ & $54.05 \pm 0.23^{\mathrm{ab}}$ & $53.07 \pm 1.66^{\mathrm{b}}$ & $57.08 \pm 0.55^{\mathrm{a}}$ & 0.059 \\
\hline Net meat weight (kg) & $300.31 \pm 11.99$ & $283.95 \pm 3.19$ & $292.43 \pm 10.39$ & 0.265 \\
\hline Net meat percentage $(\%)$ & $45.66 \pm 4.17$ & $44.48 \pm 2.88$ & $45.29 \pm 5.25$ & 0.812 \\
\hline Carcass meat percentage (\%) & $84.48 \pm 0.30$ & $83.82 \pm 0.35$ & $83.91 \pm 0.28$ & 0.856 \\
\hline Meat:bone $(\%)$ & $5.44 \pm 0.41$ & $5.18 \pm 0.50$ & $5.21 \pm 0.40$ & 0.792 \\
\hline
\end{tabular}

TMR, total mixed ration.

${ }^{1}$ SI1, cattle fed concentrate firstly then roughage. ${ }^{2}$ SI2, cattle fed roughage firstly then concentrate. ${ }^{3}$ Linear effects of three feeding systems.

${ }^{\mathrm{a}, \mathrm{b}}$ Means with different superscripts in the same row are significantly different $(\mathrm{p}<0.05)$.

Table 5. Effects of feeding methods on blood index of steers

\begin{tabular}{lcccc}
\hline Items & TMR & SI1 & SI2 $^{2}$ & p-value $^{3}$ \\
\hline TG $(\mathrm{mmol} / \mathrm{L})$ & $0.29 \pm 0.03$ & $0.28 \pm 0.01$ & $0.28 \pm 0.03$ & 0.612 \\
BUN $(\mathrm{mmol} / \mathrm{L})$ & $2.33 \pm 0.11^{\mathrm{b}}$ & $2.77 \pm 0.31^{\mathrm{a}}$ & $2.46 \pm 0.27^{\mathrm{ab}}$ & 0.026 \\
TC $(\mathrm{mmol} / \mathrm{L})$ & $2.01 \pm 0.17$ & $1.90 \pm 0.14$ & $1.97 \pm 0.16$ & 0.698 \\
NEFA $(\mu \mathrm{mol} / \mathrm{L})$ & $365.75 \pm 16.09$ & $368.67 \pm 15.23$ & $367.42 \pm 9.31$ & 0.103 \\
INS $(\mu \mathrm{IU} / \mathrm{mL})$ & $2.67 \pm 0.12$ & $2.88 \pm 0.14$ & $2.77 \pm 0.09$ & 0.145 \\
Glu $(\mathrm{mmol} / \mathrm{L})$ & $3.58 \pm 0.13$ & $3.45 \pm 0.16$ & $3.50 \pm 0.17$ & 0.942 \\
\hline
\end{tabular}

TMR, total mixed ration; TG, triglycerides; BUN, blood urea nitrogen; TC, total cholesterol; NEFA, nonesterified fatty acids; INS, insulin; Glu, glucose.

${ }^{1}$ SI1, cattle fed concentrate firstly then roughage. ${ }^{2}$ SI2, cattle fed roughage firstly then concentrate. ${ }^{3}$ Linear effects of three feeding systems

${ }^{\mathrm{a}, \mathrm{b}}$ Means with different superscripts in the same row are significantly different $(\mathrm{p}<0.05)$. 
Table 6. Effects of feeding methods on rumen fluid $\mathrm{pH}$ and VFA and $\mathrm{NH}_{3}-\mathrm{N}$

\begin{tabular}{|c|c|c|c|c|}
\hline Items & TMR & SI $^{1}$ & $\mathrm{SI} 2^{2}$ & p-value ${ }^{3}$ \\
\hline $\mathrm{pH}$ & $6.18 \pm 0.06$ & $6.00 \pm 0.10$ & $6.01 \pm 0.08$ & 0.140 \\
\hline Total VFA (mmoL/L) & $107.79 \pm 4.09$ & $108.00 \pm 13.11$ & $108.52 \pm 14.33$ & 0.952 \\
\hline Acetic acid (mmoL/L) & $66.64 \pm 2.83$ & $67.65 \pm 8.15$ & $68.00 \pm 1.82$ & 0.598 \\
\hline Propionic acid (mmoL/L) & $25.21 \pm 0.80$ & $24.23 \pm 3.51$ & $24.08 \pm 3.88$ & 0.795 \\
\hline Butyric acid (mmoL/L) & $15.84 \pm 0.79$ & $16.12 \pm 1.66$ & $16.44 \pm 2.19$ & 0.198 \\
\hline Acetic acid propionic acid & $2.64 \pm 0.10$ & $2.79 \pm 0.15$ & $2.82 \pm 0.09$ & 0.080 \\
\hline Ammonia nitrogen $(\mathrm{mg} / 100 \mathrm{~mL})$ & $8.83 \pm 3.10^{\mathrm{a}}$ & $24.00 \pm 3.89^{\mathrm{b}}$ & $21.89 \pm 4.53^{\mathrm{b}}$ & 0.037 \\
\hline
\end{tabular}

VFA, volatile fatty acids; TMR, total mixed ration.

${ }^{1}$ SI1, cattle fed concentrate firstly then roughage. ${ }^{2}$ SI2, cattle fed roughage firstly then concentrate. ${ }^{3}$ Linear effects of three feeding systems.

${ }^{\mathrm{a}, \mathrm{b}}$ Means with different superscripts in the same row are significantly different $(\mathrm{p}<0.05)$.

Table 7. Effects of feeding methods on stomach organization development

\begin{tabular}{lcccc}
\hline Items & TMR & SI ${ }^{1}$ & SI $^{2}$ & p-value $^{3}$ \\
\hline Rumen weight $(\mathrm{kg})$ & $11.86 \pm 0.58$ & $11.00 \pm 0.90$ & $11.21 \pm 0.87$ & 0.763 \\
Rumen area $\left(\mathrm{cm}^{2}\right)$ & $6,399.75 \pm 203.89^{\mathrm{a}}$ & $5,680.25 \pm 309.68^{\mathrm{b}}$ & $6,126.50 \pm 70.61^{\mathrm{ab}}$ & 0.044 \\
Rumen thickness $(\mathrm{mm})$ & $0.40 \pm 0.03$ & $0.38 \pm 0.03$ & $0.39 \pm 0.04$ & 0.923 \\
Papillary length $(\mathrm{mm})$ & $7.15 \pm 0.81$ & $6.93 \pm 0.64$ & $7.08 \pm 0.36$ & 0.444 \\
Papillary width $(\mathrm{mm})$ & $2.06 \pm 0.19$ & $1.93 \pm 0.23$ & $1.97 \pm 0.17$ & 0.226 \\
Density of papilla $\left(/ \mathrm{cm}^{2}\right)$ & $93.00 \pm 3.43$ & $89.00 \pm 6.67$ & $91.00 \pm 3.39$ & 0.770 \\
\hline
\end{tabular}

TMR, total mixed ration.

${ }^{1}$ SI1, cattle fed concentrate firstly then roughage. ${ }^{2}$ SI2, cattle fed roughage firstly then concentrate. ${ }^{3}$ Linear effects of three feeding systems.

${ }^{\mathrm{a}, \mathrm{b}}$ Means with different superscripts in the same row are significantly different $(\mathrm{p}<0.05)$.

decreased by $2.0 \%$ and $2.93 \%$, respectively, than in the SI 1 treatment group and by $0.9 \%$ and $1.65 \%$, respectively, than in the SI2 group. On the other hand, particles with small, smaller, and the smallest DM percentages $(<2.0 \mathrm{~mm}, \geq 1.0$ $\mathrm{mm} ; \quad<1.0 \mathrm{~mm}, \geq 0.5 \mathrm{~mm} ;<0.5 \mathrm{~mm}, \geq 0.25 \mathrm{~mm}$, respectively) increased by $0.54 \%, 1.9 \%$, and $2.49 \%$, respectively, in the TMR group than in the SI1 treatment group, and by $0.21 \%, 1.08 \%$, and $1.27 \%$, respectively, than in the SI2 group. At the vertical level, rumen particles with large and medium DM percentages decreased by $1.17 \%$ and $2.29 \%$, respectively, in the TMR group compared to those in the SI1 treatment group and by $0.0 \%$ and $1.88 \%$,

Table 8. Effects of feeding methods on particle distribution of steers $(\%)$

\begin{tabular}{|c|c|c|c|c|c|}
\hline$\%$ & $0.25 \mathrm{~mm}$ & $0.5 \mathrm{~mm}$ & $1.0 \mathrm{~mm}$ & $2.0 \mathrm{~mm}$ & $4.0 \mathrm{~mm}$ \\
\hline \multicolumn{6}{|c|}{ Transverse (parallel to bovine length) } \\
\hline TMR group & 13.21 & 18.17 & 20.71 & 24.97 & 22.95 \\
\hline SI1 group ${ }^{1}$ & 10.72 & 16.27 & 20.17 & 27.90 & 24.95 \\
\hline SI2 group ${ }^{2}$ & 11.94 & 17.09 & 20.50 & 26.62 & 23.85 \\
\hline$p$-value ${ }^{3}$ & 0.588 & 0.114 & 0.256 & 0.746 & 0.932 \\
\hline \multicolumn{6}{|c|}{ Vertical (vertical to bovine length) } \\
\hline TMR group & 12.74 & 17.85 & 21.14 & 25.20 & 23.09 \\
\hline SI1 group ${ }^{1}$ & 10.25 & 16.37 & 21.10 & 27.49 & 24.80 \\
\hline SI2 group ${ }^{2}$ & 11.27 & 17.72 & 20.85 & 27.08 & 23.09 \\
\hline p-value ${ }^{3}$ & 0.685 & 0.489 & 0.356 & 0.587 & 0.954 \\
\hline
\end{tabular}

TMR, total mixed ration.

${ }^{1}$ SI1, cattle fed concentrate firstly then roughage.

${ }^{2}$ SI2, cattle fed roughage firstly then concentrate.

${ }^{3}$ Linear effects of three feeding systems. respectively, compared to those in the SI2 treatment group. On the other hand, particles with small, smaller, and the smallest DM percentage increased by $0.04 \%, 1.48 \%$, and $2.49 \%$, respectively, in the TMR group compared to those in the SI1 treatment group, and by $0.29 \%, 0.13 \%$, and $1.47 \%$, respectively, compared with those in the SI2 group. This indicated that medium-sized particles were the most distributed in the rumen at both the horizontal and vertical levels. Although there was no significant difference among the three feeding methods in rumen digesta particle distribution, the TMR group tended to reduce large- and medium-sized particles and increase small-sized particles, compared with those in the SI1 and SI2 groups.

\section{DISCUSSION}

As reported in the previous performance study (Luginbuhl et al., 1990), TMR increased BW gain in growing and mature beef cattle unlike those fed in a traditional way. Our study showed that cattle on TMR treatment consumed less total DMI, concentrate, silage, crude protein, and combined net energy (NEmf) than those on SI1 and SI2 treatments (Table 3), indicating that TMR feeding methods significantly improved the economic efficiency of beef cattle breeding.

BUN levels, as an indicator of protein deposition, may reflect metabolism of protein and balance and utilization of amino acid (Chikhou et al., 1993). BUN decreased when cattle received TMR treatment in our study, indicating that 
nitrogen deposition was significantly higher during protein synthesis. Previous studies reported that carcass composition of animals was affected directly by INS and not glucagon (Bargo et al., 2002c). Table 5 showed that there was no significant difference in Glu. and INS concentrations among the three treatments, indicated carcass composition was not affected by different feeding systems. Previous studies reported that lower $\mathrm{pH}$ (less than 6.2) would increase energy consumption and reduce the rate of microbial synthesis and nitrogen deposition and inhibit the digestion of rumen cellulose (Nagaraja and Lechtenberg, 2007). Maekawa et al. (2002) reported that the rumen $\mathrm{pH}$ was too low to induce rumen acidosis when cattle were fed forage and concentrate separately. Our results showed that, there was no significant difference in $\mathrm{pH}$ among the three treatments (Table 6), and close to 6.2, indicating that these three treatments in our study may decreases the inhibitive effect on digestion of rumen cellulose unlike the other two treatments.

Our study showed that rumen $\mathrm{NH}_{3}-\mathrm{N}$ concentration was significantly lower in the cattle on TMR $(8.83 \pm 3.10 \mathrm{mg} / 100$ $\mathrm{mL})$ treatment than in those on SI1 $(24.00 \pm 3.89 \mathrm{mg} / 100$ $\mathrm{mL})$ and SI2 $(21.89 \pm 4.53 \mathrm{mg} / 100 \mathrm{~mL})$ treatments $(\mathrm{p}<0.05$; Table 6). This result is consistent with the significantly higher plasma urea $\mathrm{N}$ in the cattle on PC treatment reported in the animal performance study (Charlton et al., 2011). Combining pasture and TMR treatment increased the efficiency of $\mathrm{N}$ utilization because of the reduction in $\mathrm{N}$ losses and increase in protein yield with a similar total $\mathrm{N}$ intake. Improved $\mathrm{N}$ use, with dietary $\mathrm{TMR}$, might be a result of synchronized $\mathrm{N}$ and energy availability in the rumen (Bargo et al., 2002a, b). Dann et al. (1999) reported a mean $\mathrm{NH}_{3}-\mathrm{N}$ concentration of $10.1 \mathrm{mg} / 100 \mathrm{~mL}$ for dairy cows on a TMR diet; a similar value of $8.83 \mathrm{mg} / 100 \mathrm{~mL}$ was found for the TMR treatment in our study.

Sieve experiments suggest that there is a critical size for particles leaving the reticular rumen, since almost all size reduction of the particles occurs before they reach the omasum (Uden and Van Soest, 1982; Sekine et al., 1994). Previous studies indicated that DM digestibility tended to decrease with increasing particle size, and the critical size for increased resistance to rumen escape is larger than 1.18 $\mathrm{mm}$ (Reis et al., 2001; Maulfair et al., 2011). Some researchers have suggested that the critical particle size for rumen escape in cattle might be larger than $1.18 \mathrm{~mm}$ (Yang et al., 2001; Oshita et al., 2004). However, determining whether this speculation is true is difficult. Further, there is limited information on the effects of TMR on the critical size of particles that allows them to escape from the rumen in cattle. To our knowledge, this is the first study to discuss the rumen digesta particle distribution of TMR feeding, although there was no significant difference among these three treatments.

\section{IMPLICATIONS}

Animal performance and dietary $\mathrm{N}$ utilization were improved when cattle received TMR treatment. The TMR feeding system resulted in lower rumen $\mathrm{NH}_{3}-\mathrm{N}$ concentration than when concentrate and roughage were provided separately. Further, it improved weight gain and rumen organization development, but decreased BUN and had a trend to reduced large- and medium-sized particles and increased small-sized particles in the rumen

\section{CONFLICT OF INTEREST}

We certify that there is no conflict of interest with any financial organization regarding the material discussed in the manuscript.

\section{ACKNOWLEDGMENTS}

Financial support was provided in part by funds from China Agriculture Research System (CARS-38), Sandong Province Agriculture Research System (SDAIT-12-011-07), Shandong Provincial Natural Science Foundation (BS2014SW012) and Youth Research Foundation of Shandong Academy of Agricultural Sciences (2014QN07).

\section{REFERENCES}

Bargo, F., L. D. Muller, J. E. Delahoy, and T. W. Cassidy. 2002a. Performance of high producing dairy cows with three different feeding systems combining pasture and total mixed rations. J. Dairy Sci. 85:2948-2963.

Bargo, F., L. D. Muller, G A Varga, J. E. Delahoy, and T. W. Cassidy. 2002b. Ruminal digestion and fermentation of highproducing dairy cows with three different feeding systems combining pasture and total mixed rations. J. Dairy Sci. 85:2964-2973.

Bargo, F., L. D. Muller, J. E. Delahoy, and T. W. Cassidy. 2002c. Milk response to concentrate supplementation of high producing dairy cows grazing at two pasture allowances. J. Dairy Sci. 85:1777-1792.

Boguhn, J., H. Kluth, and M. Rodehutscord. 2006. Effect of total mixed ration composition on fermentation and efficiency of ruminal microbial crude protein synthesis in vitro. J. Dairy Sci. 89:1580-1591.

Charlton, G. L., S. M. Rutter, M. East, and L. A. Sinclair. 2011. Effects of providing total mixed rations indoors and on pasture on the behavior of lactating dairy cattle and their preference to be indoors or on pasture. J. Dairy Sci. 94:3875-3884.

Chikhou, F. H., A. P. Moloncy, P. Allcn, J. F. Quirke, F. H. Austin, and J. F. Roche. 1993. Long-term effects of cimaterol in friesian steers: I. Growth, feed efficiency, and selected carcass traits. J. Anim. Sci. 71: 906-913. 
Dann, H. M., G. A. Varga, and D. E. Putnam. 1999. Improving energy supply to late gestation and early postpartum dairy cows. J. Dairy Sci. 82:1765-1778.

Lesmeister K. E., A. J. Heinrichs, and M. T. Gabler. 2004. Effects of supplemental yeast (Saccharomyces cerevisiae) culture on rumen development, growth characteristics, and blood parameters in neonatal dairy calves. J. Dairy Sci. 87:18321839.

Luginbuhl, J. M., K. R. Pond, and J. C. Burns. 1990. Changes in ruminal and fecal particle weight distribution of steers fed coastal bermudagrass hay at four levels. J. Anim. Sci. 68:28642873.

Maekawa, M., K. A. Beauchemin, and D. A. Christensen. 2002. Effect of concentrate level and feeding management on chewing activities, saliva production, and ruminal $\mathrm{pH}$ of lactating dairy cows. J. Dairy Sci. 85:1165-1175.

Maulfair, D. D., M. Fustini, and A. J. Heinrichs. 2011. Effect of varying total mixed ration particle size on rumen digesta and fecal particle size and digestibility in lactating dairy cows. J. Dairy Sci. 94:3527-3536.

Moya, D., A. Mazzenga, L. Holtshausen, G. Cozzi, L. A. González, S. Calsamiglia, D. G. Gibb, T. A. McAllister, K. A. Beauchemin, and K. Schwartzkopf-Genswein. 2011. Feeding behavior and ruminal acidosis in beef cattle offered a total mixed ration or dietary components separately. J Anim Sci. 89:520-530.
Nagaraja, T. G. and K. F. Lechtenberg. 2007. Acidosis in feedlot cattle. Vet. Clin. North Am. Food Anim. Pract. 23:333-350.

Oshita, T., K. Nonaka, S. Kume, and T. Nakui. 2004. Effects of forage type on particle size distribution of ruminal digesta and faeces of non-lactating cows fed high quality forage. Livest. Prod. Sci. 91:107-115.

Reis, R. B., F. San Emeterio, D. K. Combs, L. D. Satter, and H. N. Costa. 2001. Effects of corn particle size and source on performance of lactating cows fed direct-cut grass-legume forage. J. Dairy Sci. 84:429-441.

Sekine, J., H. E. M. Kamel, and R. Oura. 1994. Effect of lignin content of hay on the particle size distribution of digesta in the rumen and cecum of sheep. Anim. Sci. Technol. (Jpn) 65:928941

Uden, P. and P. J. Van-Soest. 1982. The determination of digesta particle size in some herbivores. Anim. Feed Sci. Technol. 7:35-44.

Waghorn, G. C., I. D. Shelton, and V. J. Thomas. 1989. Particle breakdown and rumen digestion of fresh ryegrass (Lolium perenne L.) and lucerne (Medicago sativa L.) fed to cows during a restricted feeding period. Br. J. Nutr. 61:409-423.

Yang, W. Z., K. A. Beauchemin, and L. M. Rode. 2001. Barley processing, forage:concentrate, and forage length effects on chewing and digesta passage in lactating cows. J. Dairy Sci. 84:2709-2720. 